\title{
Weather Cycles in Relation to Agriculture and Industrial Fluctuations. ${ }^{1}$
}

TWO years ago Sir William Beveridge was led to investigate the problem of weather periodicity, from a new point of view, or at least with matérials hitherto unused-using wheat prices in past centuries as evidence of harvest yields and so of the weather. The investigation falls into three stages, namely:

(I) Construction of an index of wheat price fluctuation in Western Europe from I $55^{\circ}$ to I 869 , the index showing the price in each of those 370 years as a percentage of the average price for $3 I$ years of which it is the centre.

(2) Harmonic analysis of this index for about 300 years to $185^{\circ}$ in order to discover periodicity. In this analysis all possible trial periods between $2 \frac{1}{2}$ and 84 years in length have been examined and every apparent periodicity has been tested by analysing separately the two halves of the sequence. The result of the analysis is remarkable; not one or two but many distinct periodicities-thirteen or more-are suggested, and the suggestions are confirmed in varying degrees by the discovery of similar periodicities in meteorological records. In view of all the evidence, two of the periods-of 5.I years (found independently by Capt. Brunt and Mr. J. Baxendell), and 35.5 years (found by Dr. Brückner in I 890)-may be regarded as " certain," though not necessarily the most important. Seven others, with lengths $5.67,9.75, \mathrm{I} 2 \cdot 84, \mathrm{I} 5.23, \mathrm{I} 9.90,54^{\circ} \mathrm{o}$, and $68 \cdot 0$ years, are classed as " nearly certain"; all of these show more strongly than the Brückner and many of them more strongly than the Brunt-Baxendell cycle. Four more periods of $3.4 \mathrm{I}, 4.4 \mathrm{I}, 5.96$, and 8.05 years are "probable." There are six other " possibilities" including an II-year period, corresponding in phase and in instability as well as length to the sun-spot period.

(3) Comparison of deductions from this analysis of wheat prices before 1850 with the actual rainfall from I85I to I92I on the assumption that the meteorological factor most uniformly adverse to wheat in Western Europe is rain.

"For this purpose eleven out of the thirteen " certain," " nearly certain," and " probable " cycles, with the lengths and phases given by harmonic analysis, have been drawn for the years I85I to I92I and combined by a simple graphic method. The resulting "synthetic curve" shows a large measure of agreement with the actual rainfall for those years; for the 55 years to 1905 the coefficient of correlation is $0.3^{8}$ or about five times its probable error. The principal droughts of the last seventy years, including that of I92I, are particularly well shown and so foretold by the "synthetic curve."

This investigation, it is submitted, establishes the existence, importance, and persistence over more than 300 years, of definite periodicities in the yield of European harvests, some or all of which must be attributed to cycles in the weather. It opens up the possibility of valuable forecasts of general conditions. But no such forecasts either as to the year I923 or any other year are now possible, and Sir William Beveridge makes none. He claims for his investigation nothing more than that it affords a starting-point for more detailed studies; his hope is that competent meteorologists may be encouraged once again and more hopefully to take up these studies.

Mr. R. A. Fisher suggested that a periodicity in

1 Joint discussion of Section A (Mathematical and Physical Science), F (Economic Science and Statistics), and M (Agriculture) of the British Association at Hull on September 7 . yields is not necessarily an indication of a periodicity in weather since it may indicate merely a periodicity of economic conditions. For example, the amount of a farmer's crop is affected by the state of the labour market and the state of his own bank account. Nevertheless, if any considerable and persistent periodicity really exists in the weather, it would be likely to affect the crops and hence their prices with a similar periodicity. The crop data suitable for an investigation of this kind should be obtained, however, not under commercial but under experimental conditions. The figures obtained at Rothamsted differ from those of the Ministry of Agriculture. Detailed examination of these figures and comparison with rainfall records, indicates that rainfall apparently accounts for $30-50$ per cent. of the total variation in crop.

Examination of the distribution of the rainfall in each year shows that slow changes in yields seem to be affected only by $(a)$ the total rainfall in the year, and $(b)$ the excess of summer and winter rain over that in spring and autumn. Between the two latter there is a striking difference. In total rainfall there have been spells of wet and dry years, two wet spells about 35 years apart. But these spells can scarcely account for more than Io per cent. of the changes in the yields, though they may account indirectly for a larger percentage, e.g. by favouring weed infestation. A period of 70 years is not enough, however, to determine periodicity; in any case the quantitative value of the spells is not great, probably less than 7 per cent. of the variation in crop: the remaining 93 per cent. appears to be quite fortuitous. It is here that the weak point occurs in any argument which would make the yield of farm crops to be dependent on the weather.

The change which variation in excess of winter and summer rain over that of spring and autumn causes is more interesting than that caused by total rainfall. Examination of ten-year means reveals a steady increase for the last 70 years with no sign of slackening. The effect of an increase in December rain on the wheat yield is rather striking; on dunged plots, for example, a loss of more than $I_{\frac{1}{2}}$ bushels per acre occurred.

The general result of examining these weather records is that in most features the succession of seasons appears to be wholly fortuitous, and in all features by far the larger part appears to be fortuitous. The two cases in which distinct changes are noticeable account for a very small proportion of the variation in yield. It is of course not denied that any series of values, however arbitrary, may be expressed by Fourier's expansion as a number of harmonic cycles; but in the case of the weather, these cycles will be for the most part of short duration, and cannot be expected to reproduce themselves in the series of crop yields. For given weather the crop may be predicted with some accuracy, but Mr. Fisher is of opinion that the crop cannot be predicted even approximately without a detailed prediction of the weather.

Dr. Simpson remarked that meteorologists might be divided into two classes, those who had discovered a period and those who had not. The latter as a rule did not believe in periodicity, while the former generally believed only in the period they had themselves discovered. He exhibited on the screen a table showing 88 periods discovered by various investigators in solar and meteorological phenomena. These ranged from I 800 years to 2 hours, and he directed attention to the fact that from such a large 
number of periods-no attempt had been made to make the table complete-it would not be difficult to find a period near any specified period, especially if one were allowed to consider multiples and submultiples. He then discussed the two chief meteorological cycles, the Brückner cycle and the sunspot cycle. The hundred-year record of London rainfall has been analysed for a 35-year period, and a curve added to a diagram of monthly totals to show on the same scale the contribution of the cycle to the total rainfall. The amplitude of the cycle is absolutely insignificant in comparison with the monthly variations. Dr. Simpson admitted that there is an appreciable correlation between sunspots and meteorological factors, but as sunspots have no true periodicity they cannot introduce a periodic term into meteorological phenomena.

Turning to Sir William Beveridge's results Dr. Simpson regretted that he had not seen Sir William's recent paper in the Journal of the Statistical Society but only his papers in the Economic Journal, because the periods on which Sir William appears now to rely are different. He was prepared to admit that Sir William Beveridge had discovered certain periodicities in his curve of prices of wheat which were many times greater than one would expect by chance, but he strongly contested that these were meteorological periodicities. Sir William Beveridge laid great stress on a periodicity discovered by Capt. Brunt in Greenwich temperature, 5.I years, which coincided with one of his cycles, but it was pointed out that Capt. Brunt discovered 9 cycles, four of which had greater and four smaller amplitudes than this particular cycle. Also Capt. Brunt's cycle of 5. I years reduced the standard deviation of mean monthly temperatures at Greenwich only from 2.80 to $2 \cdot 77$, an insignificant change.

Dr. Simpson also criticised Sir William Beveridge's synthetic curve and asked why that curve should be compared with rainfall. There appeared to him no more reason why it should apply to rainfall than to any other meteorological or economic or even biological factor which might conceivably affect a harvest. In conclusion, admitting all that Sir William claimed to have done, he did not think that a prediction which gave a correlation coefficient with actuality of only 0.38 had any practical value. When Sir William had increased his correlation coefficient to about 0.83 he would be a valuable forecaster, but not until then.

Mr. Udny Yule said that the comments of Dr. Simpson seemed to him unfair. It must certainly be recognised that mere inspection of data was wholly inadequate and might lead to unfounded ideas as to the existence of periodicities, but this criticism had no bearing on work carried out by the periodogram method. He felt a good deal more doubt than some previous speakers on the question whether crop cycles were or were not a vital factor in the general economic cycle, which required far more study. From the statistical side the most important work now to be done is the determination of the crop cycles in areas other than Western Europe, e.g. South America and India: in so far as crop cycles are an important factor in the economic cycle, the resultant in any one country must be a complex effect dependent on the sources of its raw materials. On the side of economic theory it seemed to him there is also work to be done. The treatment of economics is in general static. The economist is too apt to tell us that " in the long run " a pendulum will hang vertically, whereas the whole interest of the pendulum is that it swings, and the problem is why it swings and how it swings. The treatment of economics should be dynamic. The question might be asked, for example, whether there is not an equation relating production not merely to price but to price and its time differentials, an equation which might (or in given circumstances might not) have a periodic solution.

Prof. H. H. Turner considered that we should be grateful to Sir William Beveridge, first, for producing a long series of annual values, going back much further than our longest rainfall record; secondly, for having himself analysed them completely by the periodogram method, so that others can profit by his analysis; and thirdly, for two considerable successes in the outcome. One of these is remarkable. He had succeeded in forecasting the weather in some sort-a rare, if not unique, achievement up to the present. The other success consisted in isolating several periods which must be further investigated. The periodogram gives us only the beginning, not the end of an investigation. Having obtained, for example, the definite suggestion of a I5-day period we must then see how it behaves throughout the series; the maximum phase seems to oscillate in this case. Such oscillations frequently occur in manifestations of periodicity which may itself be quite regular; thus, the rotation of the earth is quite regular, but one of its manifestations is sunrise, which swings to and fro. Sir William Beveridge had given us a good start, which it is to be hoped will be followed up.

\section{Geology of the North Sea Basin.}

THE long-standing custom of devoting at least part of a session of the Geological Section of the British Association to matters pertaining to the geology of the district in which the meeting is being held, was extended this year to the consideration of the wider question of the geological history of the North Sea basin, the discussion on this subject being the first of a series held in different sections on various aspects of the North Sea.

The discussion was opened by Prof. P. F. Kendall, president of the section, and was continued by $\mathrm{Mr}$. J. O. Borley, of the Fisheries Research Laboratory, Lowestoft, who described the nature and distribution of the deposits now being laid down. Mr. Thomas Sheppard dealt with the geology of the Hull district, and Mr. C. Thompson contributed an interesting paper on the present rate of erosion of the coast of Holderness.

The main tectonic lines of the British Isles and of the neighbouring area, the North Sea, were produced prior to the formation of the Permian rocks, the three main axes of folding being the Caledonian (N.E. and S.W.), the Pennine (N. and S.), and the Armorican (W. and E. approximately). Later movements, for the most part along these old lines, were responsible for the changes in the distribution of land and water which have taken place.

The region now occupied by the North Sea appears to have been an area of depression since a very remote period. Thus it is found that movements which took place during late Carboniferous times and during the period, unrepresented by any deposits in Europe, that elapsed before the deposition of the Permian rocks, caused the coal measures to dip into the basin in Holland and Belgium, in Northumberland and Durham, and probably also in Lincolnshire, to reemerge at Ibbenbüren. 